\title{
Teachers' Perceptions about Mathematics in a Socio-Religious Context: A Case from Pakistan
}

\author{
Munira Amirali ${ }^{1 *}$, Anjum Halai ${ }^{1}$ \\ ${ }^{1}$ Aga Khan University, PAKISTAN
}

Received 27 September 2021 • Accepted 26 November 2021

\begin{abstract}
This study investigated mathematics teachers' beliefs about the nature of mathematics and the contributory factors shaping them. A survey of 200 trained and untrained mathematics teachers from public and private schools was carried out in Karachi Pakistan, a context with a strong influence of religion on the socio-cultural practices of the people. The survey was followed by a focus-group discussion with selected teachers and is the focus of this paper. This is a groundbreaking study in a hitherto under-researched socio-religious context.

Teachers across the system showed a strong similarity in beliefs. A commonly held view was that mathematics is created by Allah and mathematicians have worked with this knowledge to invent practical applications in service of religion. Teachers' experiences of learning mathematics and their deep-rooted religious beliefs shaped their views of mathematics. The study highlights the sensitive and resilient nature of teachers' beliefs and the significance of taking them into account in reforming teacher education policy and practice.
\end{abstract}

Keywords: nature of mathematics, mathematics teachers' beliefs, socio-religious context, Pakistan

\section{INTRODUCTION}

Mathematics teachers' knowledge about the nature of mathematics and the sources that shape their viewpoints have a great influence on their teaching practices. This study was set in Karachi Pakistan which is a country with a strong influence of religion on the social and cultural practices of the people and teaching practices in the school context. This was a two-phased study including a survey of 200 teachers across the public and private schools in Karachi to explore teachers' beliefs about the nature of mathematics. The survey was followed by an in-depth qualitative focus group discussion to understand the factors that contributed to teachers' perceptions of mathematics. Finally, a smallscale intervention study was planned to work closely with two teachers, one teaching in a public school and another in a private school. The intervention phase focused on exploring the process of facilitating teachers in developing their thinking and teaching practice. This paper discusses the findings from the focus group discussion only.
Understanding teachers' beliefs about mathematics have long been the research topic as research evidence shows that teacher's personal theories about mathematics have a great influence on their teaching practice (Amirali, 2000; Barkatsas, 2008; Calleja, 2021; Gates, 2006; Halai, 2001; Hatisaru, 2018; Lloyd, 2002; \& Saadati et.al 2019; Schoenfeld, 1992). Chan and Wong (2016) alluded that, "no person is belief-free, teacher no exception. When a teacher interacts with the students in the classroom, he or she will try to behave according to what he or she believes" (244). Thompson (1984) and Ernest (1988) based on their wider experience of working in the field of mathematics education claim that any attempt in improving the quality of mathematics teaching and learning must begin with an understanding of the conceptions about nature of mathematics held by teachers. Lerman (1990) supports this view and asserts that unless teachers' knowledge about mathematics, and mathematics teaching and learning are examined, "little will be achieved in terms of development and change in the mathematics classroom" (p. 54). Hence, teachers' beliefs about the nature of knowledge (mathematics) play an important role in the development of their

(C) 2021 by the authors; licensee Modestum. This article is an open access article distributed under the terms and conditions of the Creative Commons Attribution License (http://creativecommons.org/licenses/by/4.0/).

munira.amirali@aku.edu (*Correspondence) $\square$ anjum.halai@aku.edu 


\section{Contribution to the literature}

- Several studies regarding teachers' perceptions about the nature of mathematics have been published but there are no known base-line studies in Pakistan to provide an understanding of teachers' perception of mathematics;

- This paper presents how the socio-religious context in Pakistan where predominantly Muslim live, is shaping mathematics teachers' perception of the nature of mathematics and its teaching and learning;

- The divine view of mathematical knowledge adds to the existing discourse in the mathematics education literature.

Table 1. School system structure in Pakistan

\begin{tabular}{lcc}
\hline Level & Grade / class & Age Group \\
\hline Pre-primary education & KG I-II & 3 yrs. $-4+$ yrs. \\
Primary Education & I - V & 5 yrs. $-9+$ yrs. \\
Secondary Education & VI - X & 10 yrs. $-14+$ yrs. \\
Higher Secondary Education & XI - XII & 15 yrs. $-16+$ yrs. \\
\hline
\end{tabular}

teaching practice, therefore teacher education in mathematics must take into account teachers' beliefs about the nature of mathematics and mathematics teaching and learning.

Pakistan is a predominantly Muslim country where religion plays a significant role in shaping social and cultural practices. In this context teachers' beliefs and conceptions about the nature of knowledge are also influenced by the socio-religious context. Hitherto, there is no known baseline study to provide an understanding of teachers' beliefs and understanding of the nature of mathematics and its influence on their practice. This study provides insights into teachers' beliefs about the nature of knowledge, the factors that contribute to the development of these beliefs and their implications for teacher education reform in the country.

\section{INTRODUCTION TO THE PAKISTANI CONTEXT AND BACKGROUND}

Pakistan is the fifth most populous country in the world with a population of about 220 million (GoP, 2021). Islam is the state religion and $96.4 \%$ of the population is Muslim.

The academic structure of the existing system of education in Pakistan according to NEMIS-AEPAM (2018) is as shown in Table 1.

The basic education in Pakistan is mainly offered by three systems namely government schools, private schools and Deeni Madaris (NEMIS-AEPAM, 2018). Pakistan takes explicit account of gender in setting up the public schools (Halai \& Durrani, 2020). Durrani and Halai (2020) highlight that "the government school system is largely gender segregated with schools for boys with male teachers and those for girls with female teachers" (p. 74).

Educational research conducted in the context of Pakistan also show that religious preaching and sociocultural practices influence individuals' educational viewpoints (Halai, 2008; Pardhan, 2009). With reference to their teaching practice, they considered the teacher to be the fountain of knowledge and hence students seldom get the opportunity to explore and construct mathematics knowledge and learn it for conceptual understanding. In Pakistan, there exists "the ethos of a traditional Muslim society where conceptions of knowledge are very different from those prevalent in the modern and postmodern developed countries" (Halai, 2008, p. 126). Most of the children before joining schools are taught values such as to respect elders' ideas and not to question them as they deserve respect. Those who impart knowledge are considered authority figures, and the only source of knowledge. Students consider teachers as the 'fountain of knowledge' whose role is to transmit knowledge to them (Halai, 2001). Consequently, students, as well as teachers, do not question or are not encouraged to question, the knowledge they are exposed to in the curriculum or in teacher education programmes, respectively. Some of the other contributing factors for teachers not encouraging students' questioning and promoting interactive classes is due to their (teachers') lack of subject content knowledge. Therefore, students are made to listen to their teachers without raising any questions. Also, the assessment practice is one of the key reasons that hinder developing questioning skills among students as it generally demands memorization and not understanding of the concepts. Hence, cultural and social practices, religious beliefs, teacher lack of subject content knowledge and assessment practices influence children's active participation in the learning process in schools.

With reference to mathematics teaching in the school context, research conducted in Pakistani schools shows that generally mathematics is taught through the transmission mode of teaching whereby the teachers solve one or two problems from the textbook, explain the procedures to solve problems using formula or rules, and then assign pupils to complete the exercise given in 
the textbook (Amirali, 2000; Warwick \& Reimers, 1995). Therefore, mathematics teaching emphasizes knowledge acquisition, drill and practice (Halai et al., 2007). One of the reasons discussed in the literature is that when teachers' views and preconceived notions about the subject are not taken into consideration, they shift back to their old teaching practices. Therefore, among the key focuses of mathematics teacher education in Pakistan, understanding teachers' conceptions of and how they influence their thinking and mathematics teaching and learning is an important area of research.

Recently, an important initiative undertaken by the Ministry of Federal Education and Professional Training is to develop a Single National Curriculum with an aim to provide cohesion to the school education in the country. Studying teachers' perceptions about the nature of mathematics is important as the country is in a process of launching revised Single National Curriculum Mathematics (SNC-M, 2020) where teachers are required to possess a broader perspective about mathematics and highlights that, "teachers role shifts from dispensing information to planning investigative tasks, managing a cooperative learning environment and supporting students' creativity in developing a rational understanding of the concepts"(p. 71). For that reason, there is a need to bring reform in teacher education which could be initiated by first understanding teachers' knowledge about mathematics, mathematics teaching and learning and then designing appropriate teacher education programmes to facilitate teachers to broaden their perspectives about the nature of mathematics.

In mathematics education around the world, including the Pakistani context, reforms in pre-service teacher education aim to prepare teachers who would be able to teach children to achieve the desired students learning outcome. Based on the limitation of one-year Bachelor of Education (B.Ed) programme, one of the significant initiatives of Pakistan was to launch fouryears B.Ed (Hons) degree programme for teachers who would be able to teach problem solving and critical thinking (Halai \& Durrani, 2017) Moreover, this fouryear degree programme for pre-service teachers has a strong component of practicum preparing teachers to meet the demands of the learners in the twenty-first century (Halai, 2017; HEC, 2012). In-service, professional development programmes in the public sector are usually offered through donor driven projects and cover topics or issues specified by the donor. In the private sector there is an emerging trend of, in-service programmes being offered by schools through in-house continuous professional development programmes or through schools sponsoring teachers to attend teacher development sessions in other teacher education institutions.

\section{METHODOLOGY}

The study of understanding the process of how teachers' beliefs about the nature of mathematics are shaped, described in this paper, draws from a two-phase research study exploring teachers' knowledge of the nature of mathematics, teaching, and learning of mathematics (Amirali, 2011). The two-phased research study adopted a multi-method research design. The study was conducted in Karachi, Pakistan which is a large metropolitan city that encompasses a large representation from different schooling systems. In phase I, a survey questionnaire title 'Mathematics Teacher Survey Questionnaire' with 37 items was developed that includes three themes/sections i.e., perceptions of the nature of mathematics (11 items); teaching and learning of mathematics (12 items); and teaching practice (14 items). Exploratory factor analysis was performed to reduce the data set to few factors (Field, 2005). For details see Amirali and Halai (2010). A total of 200 secondary school mathematics teachers teaching in twenty public schools and thirty private schools who were selected through the stratified sample technique to participate in the survey. The survey findings generated patterns and highlighted that the teachers held potentially contradicting views about the nature of mathematics, i.e., they consider mathematics as both a discovered and an invented body of knowledge. In Phase II these survey findings were further explored using the Focus Group Discussion (FGD) to understand the process of how teachers' views and perspectives of mathematics are shaped in the socio-cultural context of Pakistan

Randomly $20 \%$ of the schools $(n=6)$ that participated in the survey study were identified as the sample for the Focus Group Discussions (FGDs). Randomly selecting the schools instead of teachers proved to be an appropriate strategy particularly for the female teachers because at the time of the data collection Karachi was prone to frequent disturbances and it was likely that the female teachers might not get permission from their families to travel alone to other schools to participate in the semi-structured focus group discussions except in the company of colleagues. Within the selected schools, twenty-one teachers participated in the FGDs. The duration of each FGD was 60 minutes. Teachers were clustered in 3 groups: a) Professionally qualified teachers from government schools; b) Professionally qualified teachers from private schools; c) teachers who did not have any professional qualification. The research question focused in this paper is 'What are teachers' perceptions and beliefs about the nature of mathematics in a socio-religious context? What are the contributory factors shaping these beliefs and perception? A general framework was used that Finch and Lewis (2003) present for conducting focus group discussions i.e., stage one scene setting and ground rules; stage two - introduction; stage three - the opening topic; stage four - discussion; 
stage five - ending the discussion. Data were coded using Nvivo data analysis software. The initial categorization enabled us to determine patterns, personal meaning of concepts, understanding of roles and responsibilities, and reasons for ambiguities, confusions and contradictions that emerged from the survey study.

\section{LITERATURE REVIEW}

\section{Perceptions about the Nature of Mathematics}

There are various perspectives through which philosophers have discussed the nature of knowledge in general and mathematical knowledge in particular. In general, the two dominant epistemological perspectives of mathematical philosophies are 'absolutism' and 'fallibilism' (Ernest, 1991; Jaworski, 1996; Lerman, 1990). At one extreme, mathematics is seen as static, fixed and either discovered or waiting to be discovered, i.e., 'absolutist view of mathematics' and at the other extreme mathematics is seen and interpreted as socially constructed phenomena, i.e., 'fallibilist view of mathematics'. Lakatos (1976) suggested that the apparent multiplicity of philosophies of mathematics can be identified as two competing aspects that he calls Euclidean and Quasi-empirical. Proponents of Euclidean base of mathematics form the universal absolute foundation, whereas quasi-empiricist sees the growth of mathematical knowledge as a process of conjectures, proofs and refutations, and accept the uncertainty of mathematical knowledge as part of the nature of mathematics. Similarly, Dossey (1992) draws on this discussion of the nature of mathematics as far back as the fourth century BC, with Plato and Aristotle as two main contributors to these broader views of mathematics. Plato took the position that the objects of mathematics had an existence of their own beyond the mind in the external world (meta physical) and Aristotle's view of mathematics was based on "experienced reality, where knowledge is obtained from experimentation, observation and abstraction" (p.40). Both Plato and Aristotle believed that knowledge is out there. Lerman (1990) discusses two contrasting views of mathematical knowledge, i.e., absolutism and fallibilism which was used to analyze teachers' conceptions of the nature of mathematics in the study.

Understanding teachers' viewpoints and the sources of teachers' beliefs formation is important because one of the key elements discussed generally in the teacher education literature is that what teachers bring with them, their conceived knowledge about the nature of mathematics has a great influence on what they do in classrooms (Barkatsas, 2008; Dossey, 1992; Halai, 2001; Gates, 2006; Lloyd, 2002). Halai (2007), based on the emerging research findings of working with schools in a Pakistani context, writes that both teachers and students alike view mathematics as an absolute body of knowledge. Also, they view mathematical knowledge as residing in the authority of the textbook or the teachers. Consequently, "mathematics is presented as a perfectly finished body of knowledge" (p. 111). Kukari (2004) and Mansour (2008) highlighted the importance of religious and cultural views on individuals' practice. Mansour writes that world events have shown that religion can have a profound impact on many societies and that an individual's religious beliefs can certainly influence his/her own actions. Therefore, religious influences on the lives of contemporary teachers should be considered when building up an understanding of their work in the classroom. Similarly, Leu et al. (2015) indicated that "religious beliefs appear deeper than general values." (691). Kukari (2004), based on an in-depth study, highlighted the influence of religious and cultural practices in the formation of teachers' viewpoints and stated that "a dialectical and a mutually constitutive relationship existed between the religious and indigenous cultural practices and experiences of teaching and learning" (p. 107). To illustrate, Kukari described and demonstrated that, teachers' views about teaching as the transmission of prescribed knowledge from teacher to the learners and learning as the absorption and the memorization of prescribed knowledge resonate with their cultural and religious practices. Kukari further elaborated that it is a cultural norm and religious practice, for the three teachers' in her study that the learners have to sit quietly and listen attentively to those who are responsible for transmitting knowledge without questioning to show respect for adults. Then, the learners memorize and practice what is being taught. In order to bring change in teaching practice, Halai (2007) asserts "the view that the nature of mathematics knowledge is objective, fixed and rational, as introduced in the mathematics classrooms in Pakistan, need to be challenged" (p. 121).

\section{FINDINGS}

Data analysis showed three main findings. First, teachers considered mathematics as a divinely created body of knowledge where religion plays a key role in shaping their viewpoints, secondly, teachers view mathematics as important in the service of religious functions and finally their own experiences of studying mathematics in schools, their teaching experiences and participation in teacher education programmes shaping their views about nature of mathematics. Findings are presented in the following sections. To ground the findings in data and analysis, illustrative quotes are presented from the qualitative data.

\section{A Divinely Created Body of Knowledge: Role of Religion}

The teachers viewed mathematical knowledge as a divine creation. While explaining their viewpoint they referred to mathematical patterns present in nature and 
the holy Quran which was revealed to Hazrat Muhammed (Peace Be Upon Him) more than 1400 years back as a frame of reference. The teachers perceived that Almighty Allah has created the universe in which the mathematical principles and patterns are part of the creation. For example, Naureen stated that "Allah has created the universe using the mathematical structures but it is up to us how we make sense of it using our five senses". In addition, Sadia referred to Galileo to draw attention to the similar argument that, "mathematics is the language with which God has created the universe." The key idea that the teachers seemed to put forward was that the mathematical knowledge was always there and the Almighty created it. Hence, they considered mathematical knowledge exists 'out there' beyond human consciousness.

Humera shared that Allah created the universe using mathematical patterns and wants us to study the divine creation, first, to appreciate and acknowledge natural beauty and to utilize the acquired knowledge for human survival and existence. Humera further referred to one of the verses of the Holy Quran in which the divine authority who created the universe is evident.

It is He who made the sun to be a shining glory and the moon to be a light (of beauty), and measured out stages for her; that ye might know the number of years and the count (of time). Nowise did Allah create this but in truth and righteousness. (Thus) doth He explain His Signs in detail, for those who understand. (Humera's translation of the Quranic verse 10: 5)

Like Humera the other teachers also believed that the mathematical signs and patterns are present in nature. The teachers think that Allah has blessed every individual with some abilities to observe and make sense of the mathematical principles and patterns present in nature. Acknowledging the mathematical abilities, Parveen said that children have the ability to compare 'more' and 'less', 'big' and 'small', 'heavy' and 'light'. Nevertheless, teachers think that even though some mathematical competencies are innate and natural, yet through systematic observation, exploration and experimentation one can discover mathematical knowledge present in nature. For example, Khairunisa mentioned that "since the birth of Adam (alaisalam), mathematical knowledge generation process began, when human beings actually started observing the nature." While teachers believed that mathematics knowledge is a divine creation, they saw an active role of human effort in discovering mathematical knowledge present in nature.

Based on their understanding of the holy Quran and the vital discoveries the teachers highlighted the following viewpoint pertaining to the divine nature of mathematical knowledge when it was asked them to support their claim that 'mathematics existed before human came into existence' with examples.

Mohammad: Allah has created the universe in seven days so this means that mathematics was used even before humans came into existence; Almighty Allah has used mathematics in His creation. Thus, mathematics is given by Allah i.e. mathematics is God gifted.

Arzina: Allah has created the universe based on mathematical calculations. Mathematics was already there since the beginning, for example, the earth was rotating, and there was one sun and a moon.

Naureen: The sun rises and sets at an appropriate time and this is due to the pre-planned setup of the universe which neither you nor I created. This is Allah's creation which will go on and on irrespective of whether we observe it or not.

Sadia: The word 'day' (yawm) is repeated 365 times and the word 'month' (shahar) is repeated 12 times in the holy Quran.

In these responses, the teachers seemingly based their argument on the quantitative features of the universe to emphasize that Allah has carefully planned the universe using mathematical principles therefore mathematical knowledge existed before humans came into existence. In addition, the vital discovery of the duration of the earth's rotation, i.e., 365 is thought to be already hinted in the holy Quran in terms of the number of times the word 'day' is mentioned.

Furthermore, a number pattern that exists in the Holy Quran and in the human body is recognized as significant evidence of mathematical knowledge being the divine creation. The following excerpt illustrates this viewpoint:

The holy Quran which was bestowed on Hazrat Muhammed (Peace Be Upon Him) more than 1400 years back, contains numerous number patterns, for example, the number 19 pattern. There are 114 $(19 \times 6)$ chapters in the Quran; the total number of verses in the Quran is $6346(19 \times 334)$; the word 'Quran' occurs in $38(19 \times 2)$ in different chapters. All these are multiples of 19 . This pattern is also evident in Allah's creation. For example, the human body has 209 bones which is a multiple of 19 (19 times 11); [Thus] the number 19 is considered as Allah's signature. (Naureen)

The teachers further supported their explanation with some more examples of mathematical patterns present in nature which were created by almighty Allah such as: (a) ratios exist between different parts of the human body (Golden ratio); (b) symmetry in plants and 
animals - for example, the hexagonal tessellations in beehives or stripes on each side of the zebra; (c) cycle observed in nature such as seasons and the day/night. The central theme underlying the teachers' viewpoint is that mathematical knowledge is present in nature independent of human consciousness, therefore, is the discovered body of knowledge. The teachers' views about divinely revealed knowledge also appeared to lead them to consider some of the mathematical concepts taught in the school curriculum being created by Allah.

To illustrate, the following episode highlights that the ratio between circumference and diameter already exists in nature without any human involvement.

[Sadia]: Circle was invented so circumference was there, the diameter was there but we have found the ratio, i.e., pi.

[Humera]: That's what I was telling, diameter and circumference were there but ancient people did not know about Pi

[Humera]: This relationship we have discovered. basically, we have explored.

[Humera]: The relation between diameter and circumference will never change and will remain constant.

Furthermore, in the explanation teachers argued that since human invented circle, whosoever and wheresoever ratio was calculated the relationship between circumference and diameter would remain constant and would never change. Furthermore, Mohammad referred to some other mathematical relationships which existed in nature such as the Pythagoras theorem, the Fibonacci sequence in petals of some flowers, and the arrangement of seeds on flower heads. These observations led teachers to further strengthen their faith in Allah being omnipotent. Hence, divine knowledge is viewed as irrefutable truth which can never be proved wrong. The following representative responses reflect teachers' explanation for mathematical knowledge being irrefutable truth.

Sadia: As far as my own thinking is concerned with reference to 'numbers' we can tell that this will always remain true

Arzina: I don't think numbers are a human construct. Allah has blessed us with intellect; therefore; humans were able to start counting using numbers.

In summary, the teachers believed that mathematics knowledge exists 'out there' created by Allah and value human intellect in order to discover mathematical knowledge using five senses. At the same time, teachers view mathematical knowledge as being 'truth' and certain as they view it as a divine creation. Considering mathematical knowledge as a received body of knowledge being external to self potentially poses a challenge with respect to the current trends and thinking in mathematics education reform in general and in Pakistan in particular. Teachers' consideration of mathematical knowledge as irrefutable truth raises an issue of how they would engage pupils in constructing mathematics knowledge. These issues and challenges are discussed in the discussion section.

\section{Mathematics in the Service of Religious and Societal Functions}

The data analysis showed that the teachers acknowledged that mathematicians had worked to discover the divine knowledge and extend it in the service of religion and society by inventing mathematical solutions. For instance, Naureen said that "we use the mathematical knowledge which is already discovered or invented by the mathematicians" Other teachers supported this viewpoint by referring to the utilitarian purpose such as using mathematical knowledge for religious practices, for daily life survival, and for societal improvement. For example, Mohammad mentioned that in order to identify the direction of Qibla an instrument based on spherical trigonometry was invented and due to this invention locating the direction of Qibla from any part of the world was possible. Amina highlighted the importance of the Islamic calendar to determine the proper day on which to celebrate Islamic holy days and festivals such as Shab-e-Qadr, Eid-Miladun-Nabi, Jumat-ul-Wida, Eid-ul-Fitr, Eid-ul-Azha, etc. In addition, she referred to the Islamic law of inheritance where a mathematical formula is used to calculate family members' share in the property of the deceased member. She summarized that mathematics inventions support them in performing their formal act of worship i.e. 'five pillars of Islam' in order to strengthen their faith.

In these explanations, it is evident that teachers see a utilitarian value of mathematics as an instrument to carry out religious and other routine activities. If teachers use a similar approach in their teaching practice then possibly pupils would consider that following mathematics rules correctly would guarantee the correct outcome, which is all that is required in mathematics learning. This raises an issue for mathematics teaching and learning as it promotes procedural understanding as mathematics learning is not necessarily seen as an intellectual process of knowledge construction.

In explaining the utilitarian aspect of mathematics, beyond religious functions teachers saw the use of mathematics in business, commerce and other societal functions. To illustrate this Alina said that "initially when human beings started counting they used stones to count, then charcoal followed by drawing straight lines and then the figures for counting were invented". 
Similarly, Naureen explained that in order to calculate very small or big numbers which humans cannot calculate mentally some of the technological devices such as "computers -Pentium I, II, III, IV, graphic calculators were invented building on the basic mathematics computations which were already discovered earlier by our ancestors and mathematicians." Furthermore, she claimed that the technological inventions are possible due to the nature of number systems which demonstrate consistency and accuracy. In addition, Parveen highlighted the importance of mathematical knowledge in the field of science and stated that "mathematics is the mother of all sciences' because in every science field mathematics is used. For example, in chemistry, biology, physics etc." In essence, the teachers highlighted the universal feature of the numeric system, i.e., mathematics as a tool for communication and mathematics as a key source of technological innovations.

Finally, most of the teachers acknowledged the role of mathematical knowledge in the country's development with more emphasis on the monetary aspect. Almost all the teachers showed their level of agreement that mathematical knowledge facilitates in addressing major social issues such as poverty, social inequality, discrimination, etc. This indicates the teachers' consideration in terms of implementing mathematical knowledge in addressing societal issues. While exploring the reason behind their response, the teachers were not able to discuss how mathematical knowledge and skills could support addressing societal issues except for the economic aspect. This could mean that most of the teachers agree that mathematical knowledge could facilitate addressing major societal issues but might not have concrete examples to share at that point in time in the focus group discussions.

The teachers claimed that a country's economic progress depended on how well a country can manage its available resources with less dependency on other countries for assistance. Therefore, they suggested that in order to progress economically, both at an individual as well as national level, there was a need to plan the budget carefully. Based on the existing situation of Pakistan the teachers highlighted that individuals as well as representatives of the government did not utilize their mathematical competencies and skills appropriately while planning the family or the country's budgets. Hence, the country, in general, is in debt. They suggested that everyone, including children, needs to be engaged in preparing budgets. Naureen elaborated that:

Based on their financial condition parents can engage their children in the budget-making process so that they know how much pocket money they will get and will try not to spend more than the amount allocated for spending ... Just see that the whole society is in a dilemma just because we spend more than what we have. The main reason is that we do not plan our budget according to our earnings. We buy things and promise to pay from the next month's salary which is yet to come. If we know mathematics then we can prepare the family budget. If the household budget is appropriate then our government budgeting will also be appropriate...Yet our earlier loans are not repaid but still our government is taking further loans. For sure our two generations would have to bear this burden and have to repay. This is all because of the lack of utilizing mathematical knowledge. Due to this, Pakistan is under heavy debt.

Some of the teachers seemed disappointed with the prevailing situation in Pakistan and asserted that if mathematical knowledge and skills were used appropriately it would facilitate in addressing budgetary issues. To further add to the discussion Parveen referred to the media in general and television advertisement in particular which is influencing an individual's decisions and spending patterns. She thought that if individuals acquired mathematical competencies and skills such as interpreting graphs, ratios and percentage they could analyze the information and make informed decisions rather than be carried away by the advertisements. She gave an example that if students think carefully they will realize that a low-cost pen and pencil could be used for writing rather than spending on costly and fashionable stationery items.

Findings showed a certain paradox in teachers' views about mathematics. On the one hand they maintained that mathematics was divinely created and by implication not subject to change. However, they also maintained that human invention of mathematical solutions should be reviewed and challenged, as they were liable to change. For example, Reshma and Arzina, affirmed that if we carefully review invented mathematical knowledge, we too can challenge, modify or prove it incorrect similar to mathematicians.

We never try to review mathematics we know but we just go on using it without challenging it. If we research it might happen that what mathematicians have invented could be proved wrong. For example, Al-Beruni provided mathematical solutions for calculating the earth's circumference ... we don't know whether it is correct or not...there is a possibility of identifying mistakes in it. The problem with us is that we just memorize and reproduce. (Reshma)

The world ahead would certainly be different than what it is today, due to new inventions. For example, television was invented, and then computers and we right now do not know what 
will be invented in the future. Any object or viewpoint can never remain the same; it is always changing and will continue to change till the Day of Judgment. (Arzina)

In addition, Mohammad shared an example of how mathematicians invented knowledge to further extend their understanding of mathematical concepts. For example, a mathematical statement 'from any collections of things, if some are taken away, the resultant number of things left is always less than the original number of things' remained true until the integers was invented. These views resemble the fallibilist view where mathematical knowledge is considered as an evergrowing subject that challenges assumptions and provides further revision to the invented body of knowledge. Also, this indicates that the teachers consider mathematicians as knowledge constructors whereas all others as knowledge consumers.

\section{Experience of Learning, Teaching and Teacher Education in Shaping Views About the Nature of Mathematics}

Findings revealed that besides the socio-religious factors, teachers' experience of learning mathematics in schools and of learning to teach influence their thinking about mathematics. Most of the teachers shared that during schooling they had to listen to their teachers' explanation, rote memorize mathematics rules and formulae and do a lot of practice of the exercises given in the textbook. Also, they had to make efforts to get one right answers. This view is also reflected while Arzina shared her views about mathematics teaching and learning in the following interview extract

Interviewer: In the survey questionnaire most of the teachers rated as 'strongly agree' one of the items, i.e., "the most effective way to teach mathematics is to first explain the topic, give example(s) and then ask students to solve mathematical tasks". What do you think about this statement?

Arzina: Of course, we too have studied mathematics like this. Our teachers used to first make students memorize the formula and then solve the exercises given in the textbook. I too think that this is the best way to teach mathematical formulae or rules to the students.

The following statement further justifies Arzina's agreement to the mathematics teacher first explaining procedures and then engaging students in practising it.

Arzina: Every child is not smart in mathematics so first of all we teachers need to demonstrate how to solve the questions / mathematical tasks. We also need to remind students that listening to teachers attentively is necessary to learn mathematics. We also need to emphasize that after listening carefully, practice will certainly help in knowing how to solve the given tasks.

This shows that teachers believe that teacher dispenses knowledge of mathematics and learning mathematics is about memorization which is stemming from the traditional teaching methods emphasizing rules, formula and procedures that they experienced in childhood (Phelps-Gregory et al. 2020).

In addition to the classroom-based experience of learning mathematics school policies and practices also influence teachers' teaching. To elaborate, schools' decisions to affiliate either with the state testing board or with a private testing board influenced teachers' teaching practices. For example, in the public examination, the test papers are based on the content and questions included in the prescribed textbooks; therefore, teachers teach from the textbook to prepare students for that. This leads teachers to view mathematics as a collection of a set of rules which need to be memorized. Teachers teaching in the schools whose pupils take the exams from private examination board highlighted that the new testing system required teachers to adopt a new type of instructional strategies so as to engage students in mathematical problem solving and to develop a deeper understanding of the content. Therefore, teachers need to engage students in building connections and to facilitate them in applying their learning in a different situation. Handling mathematics content differently is enabling teachers to challenge their viewpoint towards mathematics as a collection of rules and formulae.

Also, teacher education promotes instrumental learning in mathematics. Based on the teachers' responses it appears that their teacher educators used a transmission mode of teaching whereby the teachers listened to lectures and took notes about how children learn, or how to teach, rather than being practically engaged in the process to conceptualize the teaching and learning processes. The following are the representative responses to explain their experiences of attending preservice courses offered by the public sector.

Zarina: basically we learn how to deliver knowledge in pre-service courses. We are shown how to teach, how to plan a lesson, how to assess, on the whole, this is taught in these programmes . .. Methods are shown to us.

Nosheen: actually when we are enrolled in preservice courses, our focus is to ... pass the examination. We are not taught through processbased or research-based methods. Moreover, at that time we were too young, so we used to study what was taught. 
Alina:: we used to study to pass the examination and now we are learning to teach (while teaching).

Khairunisa: In the B. Ed programme we are told how to teach, teacher educators observe our lessons, show our mistakes. This should not be done.

These responses apparently claim that certain practices in teacher preparation courses need to change in order to help the teachers in learning to teach. It also suggests that during these courses, even if teachers were engaged in teaching practice, the process seemed to be mechanical and its purpose to meet the requirement for examination. Nevertheless, some of the teachers acknowledged the technical skills they learnt such as how to prepare a school timetable and lesson plans. Mostly the teachers experienced a transmission mode of teaching which seemed to be influencing their views about mathematics teaching and learning.

Overall, the findings indicate that the mathematics teachers' perception of the nature of mathematics was shaped by their knowledge and practice of religion, in this case Islam. A strongly held view was that mathematics is a divinely created body of knowledge and mathematicians have worked with this knowledge to invent solutions and practical applications in service of religion and society. Additionally, findings confirmed earlier studies about the influence of prior experience of learning and of teacher education on shaping teachers' perceptions. However, in this case there was no significant difference in perception of teachers from government or private sector or among teachers who were professionally qualified and those who were not.

\section{DISCUSSION AND CONCLUSION}

This study explored the process of how teachers' views and perspectives of mathematics were shaped in the socio-cultural context of Pakistan. Teachers across the system showed a strong similarity in beliefs. The study findings conclude that a) Teachers perceive mathematics as divinely created. However, humans have worked with the divine knowledge to invent solutions and applications in service of religion and society; b) Teachers socio-religious experience contribute to the development of their perceptions of mathematics; c) Teachers experience of learning in schools and teacher-education shapes their views of mathematics; d) There did not appear to be a difference in the beliefs and perceptions for teachers from government or private sector; e) There did not appear to be difference in beliefs and perceptions of teachers who were professionally qualified and those who were not. These conclusions are now discussed, and recommendations are made for policy and practice in mathematics education including mathematics teacher education.
The findings showed that teachers from the Muslim faith on the basis of their interpretation of the sacred script - Holy Quran and the sayings of Prophet Muhammed they consider that mathematical knowledge is the divine body of knowledge and exists beyond human consciousness. This is consonant with Restivo (2017) that there are interesting but understudied cases that link mathematics and theology. Restivo (2017) further elaborates that in 1930, the physicist James Jeans argued that it was becoming clear that God is the great architect of the universe and was a pure mathematician. Also referred to Oswald Spengler's claim that mathematical innovators tend to be either religious leaders or people who experience mathematics as a religion. This divine view of mathematical knowledge adds a new dimension to the existing discourse in the mathematics education literature. Nevertheless, in other religious tradition such as Confucianism, Buddhism, Christianity, the idea of mathematical knowledge being created by God exists (Byl, 2007; Lawrence, 2015; Leu et al., 2015; Norton, 2000a, 2000b, 2003) but in the mathematics education literature, the religious views pertaining to the nature of mathematics are relatively less researched. The divine view is alike the absolutists' view of the nature of mathematics as they consider that the ultimate reality is 'out there'.

Also, teachers argued that in the past, Muslim mathematicians invented some mathematical rules, procedures and formulae especially for the performance of the most important ritual acts such as timing of the five-time prayer at specific times and in the direction of Qibla, celebrating different festivals in a year including fasting during a month Ramadan and to calculate Zakat followed by inventing mathematical knowledge for human survival. These views suggest that teachers do see mathematics as an ever growing subject with further revision to the invented body of knowledge. Also, this indicates that the teachers considered mathematicians as constructors of the invented mathematical rules, procedures and formulae whereas all others as consumers of this invented knowledge.

In addition, teachers' experiences of learning mathematics through transmission mode in teacher education institutions led them to perpetuates existing beliefs and perceptions instead of challenging them. Therefore, they view teaching as product-oriented where teachers transmit knowledge to students from textbooks, through lectures and teacher-directed questions and answer sessions (Halai, 2007; Warwick \& Reimers, 1995). In order to facilitate teachers to broaden their viewpoint about mathematical knowledge as a fallible and ever-changing body of knowledge, teacher education programmes need to engage teachers in critical discussion and reflection to challenge the preconceived notion about mathematics. Ball (1988) highlights that lack of attention to what teachers bring 
with them to learning to teach is one of the key reasons why teachers, even after undergoing professional development courses, still teach mathematics as they were taught. Hence, it can be concluded that unless the teachers' deep-rooted beliefs are taken into account the implementation of the educational reforms might not be possible. Hopefully, then teachers would see themselves as facilitators rather than dispensing information to students as is envisioned in education reforms such as the SNC-M, 2020.

Teachers had two potentially conflicting views of mathematics but both views linked to their interpretation of the sacred script - Holy Quran and the sayings of Prophet Muhammed. Teachers maintained that mathematics is a divine body of knowledge and exists beyond human consciousness. Alongside teachers also maintained that the purpose of divine creation of mathematics was to facilitate fulfillment of religious obligations. Hence, we saw in the data above that teachers believed that mathematical knowledge is a discovered body of knowledge which when discovered facilitated them to appreciate God's creation such as ratios that exist between different parts of the human body (Golden ratio) and the Fibonacci sequence. Similarly, the data excerpts above show that the primary purpose of practical application of mathematics was also seen in terms of utility for religious duties. For example, fulfill religious ritual acts - five time prayer at specific times and in the direction of Qibla, celebrating different festivals in a year including fasting during a month Ramadan and to calculate Zakat.

These findings raise significant epistemological questions with implications for teacher education practice especially in contexts where efforts are made to bring reform in mathematics teacher education, built on the philosophical foundation of knowledge as tentative and socially constructed. The view of mathematics knowledge as divine revelation assumes that the ultimate reality is 'out there' external to the knower and that the nature of knowledge is fixed. Talbani (1996) points out the dilemmas and questions that arise, when epistemological perspectives such as 'social constructivism' are introduced to learners in a society with a different perspective such as that espoused by the religious educators in Pakistan. In response to the dilemmas raised by Talbani, Irzik (1998) contends that there is a need to articulate a set of principles for a new form of science i.e., modern view 'social constructivism' in muslim context. He goes on to elaborate that this alternate form of science would have three dimensions. An epistemological dimension, i.e., the ultimate source of knowledge is Divine revelation. The ontological dimension that sees the universe as a Divine creation. Lastly, the ethical dimension according to which science and technology must serve the individual and the community in harmony with the natural order of the things. However, he raises further questions in regard to this new form of science and technology, "what would it be like and in what ways would it be different from the current one? At the moment Islamist intellectuals don't have any answers to them but they are becoming increasingly more sensitive to them" (Irzik, 1998, p. 173).

The epistemological dilemmas notwithstanding, there are practical and pragmatic considerations of taking account of teachers' religious-cultural beliefs in the course of mathematics teacher education particularly the teacher education programmes. It is well recognized that teacher education programmes (including mathematics) that are highly theoretical in content and process, and traditional in terms of not exposing teachers to critical ways of thinking about teaching, reinforce transmission and absorption view of teaching and learning mathematics. What would be the process of enabling teachers to undertake critique and questioning in the context of an absolutist and divinely revealed view of knowledge? What is the impact of teachers' dual and potentially conflicting view of mathematics on their teaching practice?

To address issues rooted in teachers' life history, religious experience and concomitant views of knowledge, have led to a strong recommendation in teacher education including mathematics, that teachers need to be given ample opportunity to reflect critically on their practice in order to reconceptualize their role in teaching and learning. However, when teachers' personal history rooted in their religious beliefs and practices promotes a view that mathematical knowledge is Allah's creation and revealed through the Quran, there is an element of sensitivity in questioning religious beliefs and knowledge. Leu et al. (2015) suggest that "both curriculum developers and advocates of certain instructional theories should be culturally and religiously sensitive to teachers' underlying religious beliefs." (p. 692). Therefore, is reconceptualization desirable or possible?

On the other hand, if a utilitarian view of mathematics is taken, albeit utility of mathematics for specific religious purposes, it could potentially promote a teaching practice where learners are expected to follow mathematics rules and procedures correctly to guarantee correct outcome. An issue for mathematics teaching and learning could be that it would promote procedural learning in mathematics as necessary and sufficient. Where would be the foundations for other dimensions of mathematics learning such as conceptual understanding, higher intellectual reasoning, proof and conjecture?

This paper has raised significant issues and questions for mathematics education arising from teachers' preconceived views about mathematics being deeply rooted in their religious, social and cultural experience. Furthermore, these issues and questions suggest the need for undertaking mathematics education research 
from a critical paradigm challenging the philosophical, epistemological and ontological assumptions based largely on the western or northern thought and create a more inclusive space for alternate conceptions of philosophy, epistemology and ontology to emerge (Halai, 2011).

On the basis of the findings recommendations for policy and practice include that mathematics teacher education could expose teachers to the historical development/s in mathematics. Studying the history of development of mathematical concepts and ideas would enable teachers to appreciate and understand the iterative nature of concept development and the importance of a problem-solving approach in mathematics. Also, the teacher education programmes have to take into account teachers' prior experiences, beliefs and conceptions as they play a key role in shaping teachers' thinking and practice (Barlow \& Reddish, 2006; Ernest, 1991; Dossey, 1992; Leatham, 2006; Leu et al., 2015). Hence, teachers need to be given ample opportunity to reflect critically on their thinking and practice in order to reconceptualize the aim of mathematics teaching and learning i.e., aim for 'creative, constructive, communicative and reflective individuals' and to enable them to apply their knowledge skillfully (SNC-M 2020).

In an under-resourced country like Pakistan, the textbook is the key resource available for most of the teachers teaching in public schools; hence, the existing textbooks need to be aligned with the SNC-M (2020) aims in order to assist teachers to promote learning mathematics for concept building. However, most of the existing textbooks have exercises that promote mastery of mathematical rules and formulae rather than engaging students to solve application-based tasks that can enhance their mathematics thinking process. Also, the provision of a range of teaching resources needs to be made available at the school level so that reliance on the prescribed textbook is shifted to multiple resources to explore mathematics for concept building.

Overall exploring teachers' perceptions about the nature of mathematics added a new dimension based on their religious, social and cultural influences particularly in a Muslim context like Pakistan. While designing teacher education programmes teacher educators particularly in the Muslim context need to be conscious, for example, while claiming the work of mathematicians being the subject of falsification because most of the teachers view Allah as the first mathematician who created the universe using mathematical principles. This study has initiated a discussion in the teacher education literature and foresee views on how to handle teachers' preconceived views about mathematics deeply rooted in their religious, social and cultural experience.

Author contributions: Both authors have sufficiently contributed to the study, and agreed with the results and conclusions.
Funding: The study was funded by the Aga Khan University Institute for Educational Development.

Declaration of interest: No conflict of interest is declared by authors.

\section{REFERENCES}

Amirali, M. (2000). Enabling mathematics teacher to teach for conceptual understanding [Unpublished master's thesis]. Aga Khan University Institute for Educational Development, Karachi, Pakistan.

Amirali, M. (2011). Investigating mathematics teachers' knowledge about mathematics, mathematics teaching and learning in schools in Pakistan [Unpublished doctoral dissertation]. The Aga Khan University Institute for Educational Development, Karachi, Pakistan.

Amirali, M., \& Halai, A. (2010). Teachers' knowledge about the nature of mathematics: A survey of secondary school teachers in Karachi, Pakistan. Bulletin of Education and Research December, 32(2), 4561.

Ball, D. L. (1988). Unlearning to teach mathematics. For the Learning of Mathematics, 8(1), 40-48.

Barkatsas, A. N. (2008). Mathematics teachers' beliefs about teaching and learning: An investigation of factors that influence these beliefs. VDM-Verlag.

Barlow, A. T., \& Reddish, J. M. (2006). Mathematical myths: Teacher candidates' beliefs and the implications for teacher educators. The Teacher Educator, 41(3), 145-157. https://doi.org/10.1080/ 08878730609555380

Byl, J. (2007). Matter, mathematics, and God. Theology and Science, 5(1), 73-86. https://doi.org/10.1080/ 14746700601159598

Calleja, J. (2021). Changes in mathematics teachers' selfreported beliefs and practices over the course of a blended continuing professional development programme. Mathematics Education Research Journal, 1-27. https:/ / doi.org/10.1007/s13394-021-00366-x

Chan, Y. C., \& Wong, N. Y. (2016). A multiple case study of teachers referring to their own religious beliefs in mathematics teaching. International Journal of Children's Spirituality, 21(3-4), 243-255. https:/ / doi.org/10.1080/1364436X.2016.1251398

Dossey, J. A. (1992). The nature of mathematics: Its role and its influence. In D. A. Grouws (Ed.), Handbook of research on mathematics teaching and learning (pp. 39-48). Macmillan.

Durrani, N., \& Halai, A. (2020). Gender equality, education, and development: Tensions between global, national, and local policy discourses in postcolonial contexts. In Grading goal four (pp. 6595). Brill Sense. https://doi.org/10.1163/ 9789004430365_003 
Ernest, P. (1988). The impact of beliefs on the teaching of mathematics [Paper presentation]. Sixth International Congress of Mathematics Education, Budapest, July 27 - August 4, 1988.

Ernest, P. (1991). The philosophy of mathematics education. The Falmer Press.

Field, A. (2005). Discovering statistics using SPSS for windows: Advance technique for beginner (2nd ed.). SAGE Publications.

Finch, H., \& Lewis, J. (2003). Focus groups. In J. Ritchie \& J. Lewis (Eds.), Qualitative research practice: A guide for social science students and researchers (pp. 4776). SAGE Publications.

Gates, P. (2006). Going beyond belief system: Exploring a model for the social influence on mathematics teacher beliefs. Educational Studies in Mathematics, 63, 347-369. https://doi.org/10.1007/s10649-005$9007-\mathrm{z}$

Government of Pakistan: Pakistan Bureau of Statistics: (2021). https:/ / www.pbs.gov.pk/

Halai A., \& Durrani N. (2020) School Education System in Pakistan. In P. Sarangapani \& R. Pappu (Eds.), Handbook of Education Systems in South Asia. Global Education Systems. Springer. https://doi.org/ 10.1007/978-981-13-3309-5_17-1

Halai, A. \& Durrani, N. (2017). Teachers as agents of peace? Exploring teacher agency in social cohesion in Pakistan. Compare: A Journal of Comparative and International Education, 48(4), 535-552. https:/ / doi.org/10.1080/03057925.2017.1322491

Halai, A. (2001). Role of social interaction in students' learning of mathematics (in classroom in Pakistan). (Doctoral dissertation). University of Oxford, UK.

Halai, A. (2011). Equality or equity: Gender awareness issues in secondary schools in Pakistan. International Journal of Educational Development, 3(1), 44-49.

https:/ / doi.org/10.1016/j.ijedudev.2010.06.012

Halai, A. (2017). Classroom as a site for teacher learning: Emergence of a paradigm shift in mathematics teacher education in Pakistan. In Professional development of mathematics teachers (pp. 159-168). Springer. https://doi.org/10.1007/978-981-102598-3 12

Halai, A., Rizvi, N. F., \& Rodrigues, S. (2007). Mathematics and science education in Pakistan: A review. https://www.edqual.org/publications/ workingpaper/edqualwp6.pdf/at_download/file. pdf

Halai, N. (2008). Curriculum reform in science education in Pakistan. In R. K. Coll \& N. Taylor (Eds.), Science education in context: An international examination of the influences of context on science curricular development and implementation (pp. 115-129). Sense
Publishers.

https://doi.org/10.1163/9789087902490_011

Hatisaru, V. (2018). Teachers' beliefs about knowledge of teaching and their impact on teaching practices. In B. Rott, G. Törner, J. Peters-Dasdemir, A. Möller, \& Safrudiannur (Eds.), Views and beliefs in mathematics education (pp. 147-159). Springer. https: / / doi.org/10.1007/978-3-030-01273-1_14

Higher Education Commission (HEC, 2012). Curriculum of education. Islamabad https:/ / hec.gov.pk/english / services/ universities/RevisedCurricula/Docum ents/2011-2012/Education/Education-2012Element.pdf

Irzik, G. (1998). Philosophy of science and radical intellectual Islam in Turkey. In W. W. Cobern (Ed.), Socio-cultural perspectives in science education (pp. 163-179). Kluwer. https:/ / doi.org/10.1007/978-94011-5224-2_9

Jaworski, B. (1996). Investigating mathematics teaching: A constructivist enquiry. The Falmer Press.

Kukari, A. J. (2004). Cultural and religious experiences: Do they define teaching and leaning for pre-service teachers prior to teacher education? Asia-Pacific Journal of Teacher Education, 32(2), 95-110. https: / / doi.org/10.1080/1359866042000234205

Lakatos, I. (1976). Proof and refutation. Cambridge University Press.

Lawrence, S. (2015). Introduction. In S. Lawrence, \& M. McCartney (Eds.), Mathematicians and their Gods Interactions between mathematics and religious beliefs, (pp. 1-21). Oxford University Press.

Leathem, K. R. (2006). Viewing mathematics teachers' beliefs as sensible systems. Journal of Mathematics Teacher Education, 9, 91-102. https: / / doi.org/10.1007/s10857-006-9006-8

Lerman, S. (1990). Alternative perspectives of the nature of mathematics and their influence on the teaching of mathematics. British Educational Research Journal, 16(1), 53-61. https://doi.org/10.1080/ 0141192900160105

Leu, Y. C., Chan, Y. C., \& Wong, N. Y. (2015). The relationships between religious beliefs and teaching among mathematics teachers in Chinese Mainland, Taiwan and Hong Kong. In L. Fan, N.-Y. Wong, J. Cai, \& S. Li (Eds.), How Chinese teach mathematics: Perspectives from insiders, (pp. 653-701). World Scientific Publishing Co. Pte. Ltd. https://doi.org/10.1142/9789814415828_0021

Llyod, G. (2002). Mathematics teachers' beliefs and experiences with innovative curriculum materials: The role of curriculum in teacher development. In G. C. Leder, E. Pehkonen, \& G. Torner (Eds.), Beliefs: A hidden variable in mathematics education? (pp. 149160). Kluwer Academic Publishers. https:/ / doi.org/10.1007/0-306-47958-3_9 
Mansour, N. (2008). The experiences and personal religious beliefs of Egyptian science teachers as a framework for understanding the shaping and reshaping of their beliefs and practices about Science-Technology- Society (STS). International Journal of Science Education, 30(12), 1605-1634. https:/ / doi.org/10.1080/09500690701463303

NEMIS-AEPAM. (2018). Pakistan Education Statistics 2013-14. National Education Management Information System, Academy of Educational Planning and Management, Ministry of Federal Education and Professional Training, Government of Pakistan. http:/ / library.aepam.edu.pk/Books/ Pakistan\%20Education \% 20Statistics \% 20201718.pdf

Norton, A. (2000a). Mathematicians' religious affiliations and professional practices: The case of Joseph. The Mathematics Educator, 12(1), 17-23.

Norton, A. (2000b). Mathematicians' religious affiliations and professional practices: The case of Charles. The Mathematics Educator, 12(2), 28-33.

Norton, A. (2003). Mathematicians' religious affiliations and professional practices: The case of Bo. The Mathematics Educator, 13(1), 41-45.

Pardhan, A. (2009). Women kindergarten teachers in Pakistan: Their lives, their classroom practice [Unpublished doctoral dissertation]. Ontario Institute for Studies in Education of the University of Toronto, Canada.

Phelps-Gregory, C. M., Frank, M., \& Spitzer, S. M. (2020). Prospective elementary teachers' beliefs about mathematical myths: A historical and qualitative examination. The Teacher Educator, 55(1), 6-27. https: / / doi.org/10.1080/08878730.2019.1618423

Restivo, S. (2017). Sociology, science, and the end of Philosophy: How society shapes brains, Gods, maths, and logics. Palgrave Macmillan.

Saadati, F., Cerda, G., Giaconi, V., Reyes, C., \& Felmer, P. (2019). Modelling Chilean mathematics teachers' instructional beliefs on problem-solving practices. International Journal of Science and Mathematics Education, 17(5), 1009-1029. https://doi.org/ $10.1007 /$ s10763-018-9897-8

Schoenfeld, A. H. (1992). Learning to think mathematically: Problem solving, metacognition, and sense-making in mathematics. In D. Grouws (Ed.), Handbook for research on mathematics teaching and learning (pp. 334-370). MacMillan.

Single National Curriculum - Mathematics Grades I-V (2020). http://www.mofept.gov.pk/SiteImage/ Misc/files/SNC\%20Mathematics\%201-5.pdf

Talbani, A., (1996). Pedagogy, power, and discourse: Transformation of Islamic education. Comparative Education Review, 40(1), 66-83. https:/ / doi.org/10.1086/447356

Thompson, A.G. (1984). The relationship of teachers' conceptions of mathematics and mathematics teaching to instructional practice. Educational Studies in Mathematics, 15(2), 105-127. https:/ / doi.org/10.1007/BF00305892

Warwick, D. P., \& Reimers, F. (1995). Hope or despair? Learning in Pakistan's primary schools. Westport, Connecticut.

\section{http://www.ejmste.com}

